\title{
Guru BK perempuan Jawa-Melayu dan laki-laki Batak lebih mempengaruhi self-disclosure konseli
}

\author{
Nelyahardi Gutji $\left.{ }^{*}\right)$, Hera Wahyuni² \\ Universitas Jambi ${ }^{12}$ \\ *) Alamat korespondensi: Jl. Muara Bulian No.Km. 15, Muaro Jambi, 36122, Indonesia; E-mail: \\ nelyahardi.fkip@unja.ac.id
}

\begin{abstract}
Article History:
Received: 22/01/2021;

Revised: 11/02/2021;

Accepted: $17 / 02 / 2021$

Published: 28/02/2021.
\end{abstract}

How to cite:

Gutji, N. \& Wahyuni, H. (2021). Guru BK perempuan Jawa-

Melayu dan laki-laki Batak lebih mempengaruhi self-disclosure konseli. Teraputik: Jurnal Bimbingan dan Konseling, 4(3), pp. 415-428. DOI:

$10.26539 /$ teraputik-43543

\section{(c) (i) This is an open} distributed under the Creative Commons 4.0 Attribution License, which permits unrestricted use, distribution, and reproduction in any medium provided the original work is properly cited. (C) 2021, Nelyahardi Gutji \& Hera Wahyuni(s).

\begin{abstract}
Abstrak: Guru BK hendaknya memahami perbedaan budaya antara dirinya dan konseli untuk memudahkan proses self-disclosure dalam konseling individu. Penelitian ini bertujuan memaparkan hasil uji empirik mengenai perbedaan self-disclosure konseli dalam konseling individu ditinjau dari jenis kelamin \& budaya guru BK/Konselor. Jenis penelitian yaitu kuantitatif dengan desain komparatif. Populasi sebanyak 765 siswa, penarikan sampel menggunakan purposive sampling dengan jumlah 224 siswa yang pernah mengikuti konseling individu. Pengumpulan data menggunakan instrumen Self-Disclosure dalam Konseling Individu (SSKI). Analisis data meliputi uji persyaratan analisis, dan uji hipotesis menggunakan Anova dua jalur. Penelitian menghasilkan perbedaan nilai rata-rata budaya Melayu perempuan 82,075 laki-laki 75,800; budaya Batak perempuan 82,067 laki-laki 86,500; dan pada budaya Jawa perempuan 87,487 laki-laki 83,086 . Kesimpulannya, konseli cenderung lebih terbuka pada guru BK berjenis kelamin perempuan dengan budaya Jawa dan Melayu Jambi. Berbeda dengan Batak, konseli cenderung lebih terbuka pada guru BK laki-laki.
\end{abstract}

Kata Kunci: Self-Disclosure, Konseling, Budaya, Gender

Abstract: Guidance \& counseling teachers should understand the cultural differences between himself and the counselee to facilitate the self-disclosure process in the individual counseling. This study aims to present the results of empirical tests regarding the differences in counselee self-disclosure in individual counseling in terms of gender and culture of the counseling. This type of research is quantitative with a comparative design. A population of 765 students, sampling using purposive sampling with a total of 224 students who have attended individual counseling. Data collection used the Self-Disclosure in Individual Counseling (SSKI) instrument. The data analysis includes the analysis requirements test, and hypothesis testing using two-way Anova. The research resulted in differences in the mean value of female Malay culture 82,075 men 75,800; Batak culture for women 82,067 men 86,500; and in Javanese culture, women were 87.487 men 83.086. In conclusion, counselees tend to be more open to female counseling teachers with Javanese and Jambi Malay cultures. Unlike the Batak, counselees tend to be more open to male counseling teachers.

Keywords: Self-Disclosure, Counseling, Culture, Gender

\section{Pendahuluan}

Tantangan yang terjadi pada masa remaja begitu kompleks dan banyak perubahan yang terjadi pada dirinya, baik psikis, maupun fisik (Zulamri, 2019). Adanya ketidakmampuan remaja mengadapi dan menyelesaikan perubahan-perubahannya dapat menimbulkan gejolak pada diri individu yang terjadi berbagai macam konsekuensi pada psikologis dan emosional yang berefek hingga stres yang akan merugikan dirinya apabila tidak mampu untuk mengendalikannya. Dengan peran konselor melakukan layanan konseling individu, diharapkan remaja terbantu untuk menyelesaikan berbagai permasalahan yang dihadapi. Konselor diharapkan membantu remaja untuk beradaptasi dengan lingkungan dalam berbagai proses perkembangan diri yang harus dilaluinya.

Konseling individu merupakan layanan dalam bimbingan \& konseling yang bertujuan membantu konseli dalam mengentaskan permasalahan yang dihadapi individu (Sukarman, 2020; Widiarni, 2020). Milne (dalam Yusuf, 2016) mengemukakan melalui konseling individu, konseli 
memperoleh bantuan dalam memecahkan masalahnya untuk menjalani kehidupan yang lebih bermakna. Agar tujuan dalam konseling individu tercapai, guru BK harus memiliki kemampuan komunikasi yang baik. guru BK menghargai keragaman klien dan tidak memaksakan nilai-nilai yang dibawa oleh guru BK kepada klien (Corey, 2017). Mitchell \& Gibson (2011) menjelaskan guru BK profesional perlu mengingat bahwa perbedaan suku, dialek dan bahasa di antara konselor dan klien berpengaruh besar bagi kesuksesan proses konseling. Senada dengan pendapat Baruth \& Manning (2016), faktor yang mempengaruhi keberhasilan konseling perbedaan pola komunikasi yang berbeda, di antaranya: 1) seksualitas, 2) ras, 3) gender, dan 4) sosial-ekonomi.

Komunikasi gender merupakan komunikasi antara laki-laki \& perempuan (Hodiyanto, 2017). Menurut Wood (2012), laki-laki dan perempuan belajar berinteraksi membagi pengalaman melalui berbagai gaya komunikasi yang sering mengakibatkan kegagalan dalam prosesnya. guru BK harus memahami perbedaan budaya yang dibawanya dengan budaya klien agar tujuan dalam proses konseling tercapai.

Keberhasilan konseling tidak hanya ditentukan dari guru BK saja, tetapi juga dari konseli. Semakin baik self-disclosure konseli dalam konseling individu, persentase keberhasilan konseling individu tersebut dalam penyelesaikan masalah semakin tinggi (Auladi, 2019). Selfdisclosure konseli adalah proses fundamental dan kritis yang harus terjadi jika konseling ingin berhasil (Zane \& Ku, 2014). Forgas (2011) mendeskripsikan bahwa individu-individu dalam keadaan suasana hati yang positif self-disclosure mereka dalam menyampaikan informasi lebih intim, lebih bervariasi, dan lebih abstrak tentang diri mereka. Self-disclosure membuat hubungan antarpribadi yang sangat akrab dan intim karena adanya interpretasi makna, self-disclosure sebagai pintu masuk seseorang dalam mengenal dirinya dan mengenal orang lain (Silfia, 2017).

Salah satu aspek yang dapat ditingkatkan pada remaja untuk menunjang kelancaran konselor dalam melakukan layanan konseling individu adalah self disclosure. Sukardi (Zulamri, 2019) mengungkapkan bahwa layanan konseling individual dengan self disclosure sangat berkaitan erat. Hal ini karena di dalamnya harus terjadi proses saling keterbukaan agar tujuan konseling bisa tercapai secara optimal. Keterbukaan ini bukan sekedar menerima masukan dari luar, tetapi bersedia membuka diri secara jujur tentang dirinya untuk konseling.

Self-disclosure adalah komunikasi yang mengungkap pemikiran, perasaan, dan keinginan diri sebenarnya (Gamayanti et al., 2018). Christiana (2016) menjelaskan self-disclosure adalah pengungkapan diri individu khususnya dapat mengungkapkan informasi tentang dirinya melalui ekspresi, gerak tubuh, pakaian, suara, serta melalui isyarat-isyarat nonverbal. Definisi selfdisclosure pada penelitian ini merupakan keterbukaan diri konseli kepada guru BK menceritakan permasalahan yang dialami dalam konseling individu dilihat dari aspek keluasan, kedalaman, target, ketepatan, dan waktu.

Penelitian di German (Horne \& Johnson, 2018) yang menguji 5.042 individu terkait perbandingan faktor self-disclosure dengan sikap peran gender. Perempuan lebih bisa mengungkap diri daripada laki-laki. Hal ini lebih menjadikan suatu hubungan antara laki-laki \& perempuan lebih erat dan berhasil daripada hanya sekedar menjalankan sikap peran gender sebagaimana mestinya. Contoh, perempuan hanya masak, laki-laki hanya bekerja, tetapi tidak ada komunikasi keterbukaan di antara keduanya. Keberhasilan hubungan dari adanya kondisi ini lebih rendah daripada laki-laki dan perempuan saling ada self-disclosure. Temuan ini semakin memperkuat betapa pentingnya self-disclosure bagi keberhasilan hubungan, khususnya hubungan konseling.

Berdasarkan penelitian dari Chalidaziah et al., (2018) self-disclosure konseli dengan budaya Aceh baik laki-laki dan perempuan berada pada kategori rendah. Siswa perempuan cenderung lebih terbuka tentang dirinya daripada siswa laki-laki. Berbeda dengan hasil penelitian (Siagian, 2017), di mana tidak terdapat perbedaan self-disclosure dalam konseling individu antara konselor-konseli yang sama jenis kelaminnya dengan yang berbeda jenis kelaminnya. Hal ini membuktikan bahwa budaya guru BK dan siswa dapat mempengaruhi tingkat self-disclosure dalam konseling individu.

Faktor yang mempengaruhi self-disclosure, di antaranya: kecemasan, neuroticism, ekstroversi, impulsif, dan keinginan sosial (Forgas, 2011; Irshad, 2011; Nöstlinger et al., 2015). Selanjutnya, (Kesumadewi, 2018) menyatakan bahwa wanita cenderung lebih menekankan 
komunikasi intim dengan teman sesama wanita ketimbang laki-laki. Menurut (Mangkunegara \& Puspitasari, 2015), efek merugikan dari menjaga rahasia yaitu sebagai pemicu stres dari waktu ke waktu. Pikiran yang tidak diinginkan, berulang, perasaan cemas dan depresi, masalah tidur, dan banyak masalah fisiologis, psikologis, dan fisik lainnya telah dilihat sebagai hasil menyembunyikan informasi penting dari orang lain.

Apabila gaya konseling guru BK tidak cocok dengan gaya komunikasi konseli yang memiliki latar berlakang budaya berbeda, proses konseling akan terhambat (Hadiwinarto, 2018). Hal ini mengakibatkan tingkat self-disclosure (pengungkapan diri) rendah, terminasi dini, dan lainlain. Keberhasilan konseling ditentukan dari bagaimana konseli atau siswa mampu mengungkapkan dirinya atau menceritakan keadaan dirinya kepada guru BK/ konselor.

Perkembangan penelitian di dunia terkait variabel self-disclosure memberikan inspirasi untuk mengembangkan topik dalam penelitian ini. Berdasar penelitian sebelumnya, terdapat kebaruan (novelty) yang dihasilkan. Adapun topik penelitian ini berasal dari berbagai literasi jurnal ilmiah dapat dijelaskan sebagai berikut. (1) Penelitian dari (Wahyuni, 2018) memaparkan beberapa poin, yaitu: a) self-disclosure di forum dukungan lebih tinggi daripada di forum diskusi, b) tidak ada perbedaan gender dengan tingkat self-disclosure (c) timbal balik dari self-disclosure menghasilkan korelasi positif self-disclosure, (d) beberapa perbedaan muncul dalam tingkat timbal balik dari self-disclosure siswa perempuan cenderung lebih timbal balik dari pada siswa laki-laki. (2) Penelitian Forest \& Wood (2012) siswa dengan self esteem rendah menganggap Facebook sebagai tempat yang menarik untuk, rendahnya kepositifan dan negatif yang tinggi dari pengungkapan mereka menimbulkan tanggapan yang tidak diinginkan dari orang lain di media sosial. (3) Penelitian dari Ziv-Beiman (2013) dipahami bahwa self-disclosure berasal dari integrasi dari berbagai dimensi yang terapeutik, di mana secara bersamaan self-disclosure memperkuat hubungan terapeutik dan memajukan dimensi perubahan. (4) Penelitian Ying et al., (2016) diperoleh hasil bahwa self-disclosure sangat penting dalam keberhasilan membina persahabatan di jejaring sosial. (5) Penelitian dari Zane \& Ku (2014) diperoleh hasil kecocokan etnis, kecocokan gender, akulturasi, identitas budaya, dan keprihatinan mempengaruhi self-disclosure dalam konseling individu untuk orang Amerika keturunan Asia. (6) Penelitian Gibson (2012) diperoleh hasil bagaimana pengungkapan diri konselor. (7) Penelitian Heath et al. (2016) diperoleh hasil sikap mencari bantuan dan self-disclosure siswa Uni Emirat Arab dipengaruhi oleh stigma konseli terhadap konselor. (8) Barnett (2011) menjelaskan tentang pertimbangan etis dan klinis dalam self-disclosure pada hubungan konseling. (9) Penelitian Kim \& Dindia (2011) tentang selfdisclosure online. (10) Penelitian Tang et al. (2013) tentang budaya \& self-disclosure seksual dalam hubungan intim. (11) Penelitian Horne \& Johnson (2018) tentang self-disclosure dengan peran gender dan keberhasilan hubungan dalam hubungan intim. (12) Penelitian (Levitt et al., 2016) tentang self-disclosure terapis mempengaruhi keberhasilan konseling. (13) Penelitian tentang (Bitar et al., 2014) tentang Self-disclosure konselor pada budaya Meksiko di pengadilan Amerika. (14) Penelitian Quek \& Fitzpatrick (2013) menyebutkan nilai-nilai budaya, selfdisclosure, dan taktik konflik sebagai prediktor kepuasan perkawinan antara suami dan istri Singapura. (15) Penelitian Morman et al. (2013) menghasilkan self-disclosure memediasi efek orientasi gender dan homofobia. (16) Penelitian Hill et al. (2018) tentang self-disclosure dan kedekatan dengan konselor. (17) Penelitian Sunderani \& Moodley (2020) tentang persepsi konselor tentang penggunaan self-disclosure (dan menyimpan kerahasiaan) mereka selama pertukaran lintas budaya.

Penelitian di atas menggambarkan tentang perkembangan self-disclosure di berbagai negara pada latar belakang etnis yang berbeda. Penelitian tersebut menjelaskan tingkat selfdisclosure individu lebih tinggi pada jejaring sosial. Individu merasa menggunakan jejaring sosial memudahkan mereka dalam membina persahabatan. Terdapat kebaruan yang belum pernah ada sebelumnya dalam penelitian ini. Kebaruan tersebut adalah self-disclosure siswa dalam konseling individu ditinjau dari aspek jenis kelamin konselor serta budaya konselor yang berbeda dengan konseli. Judul penelitian ini belum pernah diteliti pada penelitian lain sebelumnya.

Rumusan masalah penelitian ini dirumuskan "Apakah terdapat perbedaan self-disclosure siswa dalam konseling individu ditinjau dari jenis kelamin guru BK dan budaya guru BK?" Tujuan penelitian ini adalah untuk memaparkan hasil uji empirik mengenai perbedaan self-disclosure konseli dalam konseling individu ditinjau dari jenis kelamin guru BK dan budaya guru BK. Jenis 
kelamin guru BK, yaitu laki-laki atau perempuan. Budaya guru BK yang dimaksud adalah guru BK berlatar belakang suku budaya Melayu Jambi, Jawa, dan Batak.

Adapun lingkup manfaat penelitian ini dapat dirasakan oleh guru Bimbingan Konseling dan pengembangan ilmu pengetahuan Bimbingan dan Konseling. Bagi Guru Bimbingan Konseling, temuan penelitian ini dapat berimplikasi pada urgensinya peningkatan hard skill dan soft skill dalam menggunakan keterampilan konseling multikultural, maupun konseling lintas budaya. Selain itu, tidak hanya mengupas budaya berdasarkan suku atau asal daerah, penelitian ini dilengkapi dengan keterkaitan pada isu gender. Bagi pengembangan ilmu pengetahuan Bimbingan dan Konseling, yaitu konsep dan tema self-disclosure dengan budaya dan gender dapat memberikan kontribusi pengetahuan terkait faktor budaya yang mempengaruhi hasil layanan konseling individu.

Hipotesis penelitian ini terdiri dari hipotesis kerja dan hipotesis nihil. Hipotesis kerja di sini dapat disimbolkan sebagai berikut: " $\mathrm{H}_{1}=\mu_{1} \neq \mu_{2} \neq \mu_{3} \neq \mu_{4} \neq \mu_{5} \neq \mu_{6} \neq \mu_{r}$ ". Hipotesis kerja $\left(\mathrm{H}_{1}\right)$ tersebut dibaca "Terdapat perbedaan self-disclosure siswa dalam konseling individu ditinjau dari jenis kelamin guru BK (laki-laki \& perempuan) dan budaya guru BK (Jawa, Melayu, \& Batak)". Hipotesis nihil di sini dapat disimbolkan sebagai berikut: " $H_{0}=\mu_{1}=\mu_{2}=\mu_{3}=\mu_{4}=\mu_{5}=\mu_{6}=\mu_{\mathrm{r}}$ ". Hipotesis nihil $\left(\mathrm{H}_{0}\right)$ tersebut dibaca "Tidak terdapat perbedaan self-disclosure siswa dalam konseling individu ditinjau dari jenis kelamin guru BK (laki-laki \& perempuan) dan budaya guru BK (Jawa, Melayu, \& Batak)".

\section{Metode}

Penelitian bertujuan untuk memaparkan perbedaan self-disclosure konseli dilihat berdasarkan dari jenis kelamin \& budaya guru BK. Metode penelitian yang tepat adalah kuantitatif dengan pendekatan comparative research design (Hamilton \& Ravenscroft, 2018). Penelitian dilakukan pada enam sekolah yang berbeda. Sekolah yang mewakili kriteria terdapat guru BK berlatar belakang suku budaya Melayu adalah SMA Negeri 2 Muaro Jambi dan SMA Negeri 6 Muaro Jambi. Sekolah yang mewakili kriteria terdapat guru BK berlatar belakang budaya Batak adalah SMA Negeri 4 Kota Jambi dan SMA Negeri 1 Muaro Jambi. Sekolah yang mewakili kriteria terdapat guru BK berlatar belakang budaya Jawa adalah SMA Negeri 8 Kota Jambi dan SMA Negeri 10 Kota Jambi.

Populasi penelitian ini berjumlah 765 siswa. Penarikan sampel menggunakan purposive sampling. Sampel penelitian ini berjumlah 224 orang siswa. Sampel yang dipilih ditentukan berdasarkan kriteria, yaitu siswa yang sudah pernah mengikuti konseling individu dengan guru Bimbingan Konseling laki-laki dan perempuan berlatar belakang budaya suku Melayu Jambi, Batak, dan Jawa. Jumlah sampel penelitian ini diuraikan pada Tabel 1. Sampel Penelitian berikut.

Tabel 1. Sampel Penelitian

\begin{tabular}{lll}
\hline Budaya Guru BK/ Konselor & $\begin{array}{l}\text { Jenis Kelamin Guru BK/ } \\
\text { Konselor }\end{array}$ & $\begin{array}{l}\text { Jumlah Siswa yang } \\
\text { mengikuti Konseling Individu }\end{array}$ \\
\hline Melayu & Laki-laki & 35 \\
\cline { 2 - 3 } & Perempuan & 40 \\
\cline { 2 - 3 } & Total & 75 \\
\hline \multirow{2}{*}{ Batak } & Laki-laki & 30 \\
\cline { 2 - 3 } & Perempuan & 45 \\
\cline { 2 - 3 } & Total & 75 \\
\hline \multirow{2}{*}{ Jawa } & Laki-laki & 35 \\
& Perempuan & 39 \\
\cline { 2 - 3 } & Total & 74 \\
\hline Jumlah & Laki-laki & 100 \\
\cline { 2 - 3 } & Perempuan & 124 \\
\cline { 2 - 3 } & Jumlah Keseluruhan & 224 \\
\hline
\end{tabular}


Pengumpulan data menggunakaan Skala Self-Disclosure dalam Konseling Individu (SSKI) dengan lima alternatif jawaban, yaitu sangat sesuai, sesuai, ragu-ragu, tidak sesuai, dan sangat tidak sesuai. Untuk mengukur tingkat kebaikan instrumen, maka dilakukan uji coba instrumen dengan mengadministrasikan skala SSKI. Tingkat kebaikan instrumen yang dimaksud adalah uji validitas dan reliabilitas. Uji validitas adalah validitas konstruk dengan rumus product moment (pearson). Uji reliabilitas dengan internal consistency, melihat nilai dari Cronbach's alpha.

Instrument SSKI diuji coba selama tiga hari pada tanggal 12 Mei 2020 hingga 15 Mei 2020 kepada enam puluh orang siswa di Sekolah Menengah Atas Negeri 2 Muaro Jambi menggunakan google form. Pengambilan keputusan juga dilihat dari Sig. (2-tailed). Jika Sig. (2-tailed) $\leq 0,05$ (taraf signifikansi), maka item valid. Jika Sig. (2-tailed) $\geq 0,05$ (taraf signifikansi), maka item dikatakan tidak valid. Keseluruhan item pada variabel self-disclosure adalah valid.

Untuk interpretasi reliabilitas dilihat pada nilai Cronbach's alpha. Apabila skor uji kurang dari 0,6 adalah kurang baik, skor 0,7 dapat diterima, dan skor di atas 0,8 adalah baik. Reliabilitas skala SSKI sebesar 0,875. Jadi, dapat disimpulkan skala SSKI setelah uji reliabilitas dapat dikatakan baik.

Prosedur penelitian ini adalah terlebih dahulu dilakukan studi literatur, menyusun rencana penelitian, menyusun instrumen, penentuan kelompok yang memiliki karakteristik yang ingin diteliti, melakukan uji coba instrumen, membagikan angket skala Self-Disclosure dalam Konseling Individu (SSKI) kepada siswa di SMA Negeri 2 Muaro Jambi melalui google form, analisis data, penyusunan laporan penelitian, hingga pembuatan artikel. Penelitian dilakukan mulai bulan April 2020 s.d. Januari 2021, yaitu selama sembilan bulan. Peralatan penelitian ini, antara lain: literatur dari buku dan internet, instrumen validasi, dan instrumen angket skala Self-Disclosure dalam Konseling Individu (SSKI). Bahan penunjang yang digunakan dalam penelitian, antara lain: kertas HVS, alat tulis, tinta print warna, penjepit kertas, map, dan dokumen keeper.

Analisis data dilakukan menggunakan uji hipotesis dengan two-way Analysis of Variance (Anova) 2x3 (Hermawan, 2019). Lingkup penelitian ini adalah budaya guru Bimbingan Konseling hanya diwakili dari budaya Melayu Jambi, Jawa, dan Batak. Masing-masing budaya tersebut hanya diwakili dari dua sekolah. Karena ada tiga budaya, jadi tempat penelitian tidak lebih dari enam sekolah. Latar tempat penelitian adalah dari Jambi. Guru BK dengan suku lain yang kebetulan ada di sekolah tempat penelitian, bukan peneliti yang pergi ke Pulau Jawa, misalnya.

Keterbatasan metode penelitian ini adalah kesulitan dalam mencari siswa yang benarbenar pernah menjalankan konseling individual kepada guru BK laki-laki \& perempuan dalam latar belakang suku rubudaya yang dimaksud. Ada siswa yang belum pernah mengikuti konseling individual sama sekali. Ada juga siswa yang baru mengikuti konseling individual kepada konselor dengan salah satu gender, laki-laki atau perempuan, sementara gender sebaliknya belum. Oleh karena itu, untuk meminimalisir keterbatasan tersebut, populasi sebelumnya diberi pertanyaan apakah pernah mengikuti konseling individual kepada konselor laki-laki \& perempuan yang memiliki latar belakang budaya konselor tersebut. Siswa yang menjawab pernah, berhak masuk dalam sampel penelitian. Siswa yang menjawab belum pernah atau tidak pernah sama sekali, tidak masuk dalam sampel penelitian. Keterbatasan penelitian yang kedua adalah kelompok sekolah dan sampel tidak boleh dipilih secara random, melainkan secara purposif (bertujuan). Hal ini berdampak negatif pada lingkup penelitian menjadi sulit untuk digeneralisasi. 


\section{Hasil dan Diskusi}

Subbab hasil dan diskusi ini membahas tentang hasil analisis data untuk menguji hipotesis penelitian menggunakan two way Analysis of Variance (Anova) 2x3. Data yang telah terkumpul dianalisis uji normalitas \& homogenitas terlebih dahulu agar memenuhi persyaratan uji analisis data. Setelah itu, masuk pada poin uji hipotesis dan pembahasan hasil penelitian.

Uji normalitas dijelaskan dalam Tabel 2. Hasil Uji Normalitas sebagai berikut.

Tabel 2. Hasil Uji Normalitas

\begin{tabular}{|c|c|c|c|c|c|c|c|c|c|c|c|}
\hline \multirow{2}{*}{$\begin{array}{c}\text { Self- } \\
\text { disclosure }\end{array}$} & \multirow{2}{*}{$\frac{\bar{J}}{\frac{\pi}{0}}$} & \multirow{2}{*}{ 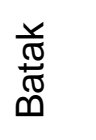 } & \multirow[t]{2}{*}{ 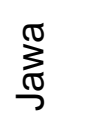 } & \multirow[t]{2}{*}{ LK } & \multirow[t]{2}{*}{$P$} & \multicolumn{4}{|c|}{$\begin{array}{c}\text { Budaya } \\
\text { Batak }\end{array}$} & \multicolumn{2}{|c|}{ Jawa } \\
\hline & & & & & & LK & $P$ & LK & $P$ & LK & $P$ \\
\hline $\mathrm{N}$ & 75 & 75 & 74 & 100 & 124 & 35 & 40 & 30 & 45 & 35 & 39 \\
\hline Norma Me- & 79,1 & 83,8 & 85,4 & 81,5 & 83,7 & 75,8 & 82,0 & 86,5 & 82,07 & 83,0 & 87,4 \\
\hline $\begin{array}{l}\text { I Para- an } \\
\text { meters }\end{array}$ & 5 & 4 & 1 & 6 & 7 & & 8 & & & 9 & 9 \\
\hline Std. & 15,6 & 16,7 & 13,5 & 17,0 & 14,1 & 18,7 & 11,8 & 17,5 & 16,13 & 13,2 & 13,5 \\
\hline Deviation & 65 & 6 & 03 & 76 & 74 & 27 & 76 & 98 & 9 & 7 & 39 \\
\hline M. E. $\quad A b-$ & 0,07 & 0,10 & 0,07 & 0,07 & 0,05 & 0,08 & 0,08 & 0,14 & 0,098 & 0,08 & 0,09 \\
\hline $\begin{array}{cc}\text { Diffe- } & \text { so- } \\
\text { rences } & \text { lute }\end{array}$ & 5 & 8 & & 8 & 5 & 5 & 9 & 4 & & 7 & 3 \\
\hline Positive & 0,04 & 0,05 & 0,07 & 0,05 & 0,04 & 0,08 & 0,06 & 0,11 & 0,076 & 0,07 & 0,09 \\
\hline Negative & $-0,08$ & $-0,1$ & $-0,05$ & $-0,08$ & $-0,06$ & $-0,1$ & 0,09 & $-0,1$ & $-0,10$ & 0,08 & 0,05 \\
\hline $\begin{array}{c}\text { Kolmogorov- } \\
\text { Smirnov Z }\end{array}$ & $\begin{array}{c}0,64 \\
8\end{array}$ & $\begin{array}{c}0,93 \\
2\end{array}$ & $\begin{array}{c}0,59 \\
8\end{array}$ & $\begin{array}{c}0,77 \\
8\end{array}$ & $\begin{array}{c}0,61 \\
3\end{array}$ & 0,5 & $\begin{array}{c}0,56 \\
5\end{array}$ & $\begin{array}{c}0,78 \\
9\end{array}$ & 0,66 & $\begin{array}{c}0,51 \\
7\end{array}$ & $\begin{array}{c}0,58 \\
1\end{array}$ \\
\hline $\begin{array}{c}\text { Asymp. Sig. } \\
\text { (2-tailed) }\end{array}$ & $\begin{array}{c}0,79 \\
5\end{array}$ & 0,35 & $\begin{array}{c}0,86 \\
7\end{array}$ & $\begin{array}{c}0,58 \\
1\end{array}$ & $\begin{array}{c}0,84 \\
7\end{array}$ & $\begin{array}{c}0,96 \\
4\end{array}$ & $\begin{array}{c}0,90 \\
7\end{array}$ & $\begin{array}{c}0,56 \\
2\end{array}$ & 0,777 & $\begin{array}{c}0,95 \\
2\end{array}$ & $\begin{array}{c}0,88 \\
8\end{array}$ \\
\hline
\end{tabular}

Berdasarkan Tabel 2. Hasil Uji Normalitas di atas, hasil perhitungan uji normalitas variabel penelitian ditemukan bahwa nilai Asymp. Sig. (2-tailed) untuk variabel = 0,795, 0,35, 0,867, 0,581, $0,847,0,964,0,907,0,562,0,777,0,952$, dan 0,888 . Nilai yang diperoleh ini lebih besar dari harga $\alpha=0,05$. Dengan demikian, dapat disimpulkan semua kelompok dari populasi berdistribusi normal. Data ini lolos uji normalitas, sehingga dapat digunakan dan dilanjutkan untuk pengujian homogenitas.

Selanjutnya, dilakukan uji homogenitas sebagai prasyarat untuk dilakukan analisis ke tahap berikutnya. Uji homogenitas variabel berdasarkan dari jenis kelamin (laki-laki dan perempuan) $\left(\mathrm{X}_{1}\right)$ dan budaya konselor (Batak, Melayu, dan Jawa) $\left(\mathrm{X}_{2}\right)$ terhadap tingkat selfdisclosure siswa $(\mathrm{Y})$. Nilai koefisien $\mathrm{F}_{\text {hitung }}=2,60$ pada tabel Anova pada taraf signifikan $0,026<$ 0,05 . Hasilnya, semua taraf signifikan $<0,05$ didukung oleh data pada tabel Levene 1,86 pada taraf signifikan 0,102 . Dengan demikian, dapat disimpulkan semua variabel yaitu jenis kelamin (laki-laki dan Perempuan) $\left(\mathrm{X}_{1}\right)$ dan Budaya Konselor (Batak, Melayu, dan Jawa) $\left(\mathrm{X}_{2}\right)$ terhadap tingkat self-disclosure siswa $(\mathrm{Y})$ homogen. Jika data semua kelompok dalam variabel penelitian diketahui homogen, maka data penelitian ini dianggap lolos uji homogenitas.

Setelah data penelitian lolos uji normalitas \& homogenitas, dilakukan pengujian hipotesis. Pengujian hipotesis penelitian ini dilakukan dengan teknik Anova dua jalur. Penggunaan teknik Anova dua jalur bertujuan untuk mengetahui kontribusi individual dari variable bebas terhadap hasil eksperimen (main effect). Hipotesis dalam penelitian ini terdapat perbedaan self-disclosure siswa dalam konseling individu berdasarkan dari jenis kelamin laki-laki \& perempuan dan budaya guru BK Melayu, Batak, dan Jawa. 

berikut ini.

Untuk melihat hasil uji hipotesis penelitian dapat dilihat pada Tabel 3. Uji Anova Dua Jalur

Tabel 3. Uji Anova Dua Jalur

\begin{tabular}{lccccc}
\hline Source & Type III Sum of Squares & Df & Mean Square & $F$ & Sig. \\
\hline Corrected Model & $3030.553 a$ & 5 & 606,111 & 2,6 & 0,026 \\
\hline Intercept & 1512332,085 & 1 & 1512332 & 6487 & 0 \\
\hline$A$ & 1728,512 & 2 & 864,256 & 3,707 & 0,026 \\
\hline$B$ & 238,624 & 1 & 238,624 & 1,024 & 0,313 \\
\hline${ }^{*} B$ & 1191,254 & 2 & 595,627 & 2,555 & 0,048 \\
\hline Error & 50819,161 & 218 & 233,115 & & \\
\hline Total & 1589028 & 224 & & & \\
\hline Corrected Total & 53849,714 & 223 & & & \\
\hline
\end{tabular}

Berdasarkan Tabel 3 di atas, didapatkan nilai $F_{\text {hitung }}=3,707$ pada taraf signifikan $0,026<$ dari $\alpha=0,05$. Dengan demikian, dapat disimpulkan bahwa terdapat perbedaan signifikan pada self-disclosure siswa dalam konseling individu berdasarkan dari jenis kelamin laki-laki \& perempuan dan budaya guru BK suku Melayu Jambi, suku Batak, dan suku Jawa.

Selanjutnya, dilakukan uji deskriptif untuk memaparkan jenis kelamin manakah yang lebih unggul dari setiap budaya guru BK suku Melayu Jambi, suku Batak, dan suku Jawa. Berikut ini tabel 4. Uji Deskriptif.

Tabel 4. Uji Deskriptif

\begin{tabular}{llcrcc}
\hline \multirow{2}{*}{ Budaya Guru BK } & Jenis Kelamin & \multirow{2}{*}{ Mean } & \multirow{2}{*}{ Std. Error } & \multicolumn{2}{c}{ 95\% Confidence Interval } \\
& Guru BK & & & Lower Bound & Upper Bound \\
\hline \multirow{2}{*}{ Melayu } & Laki-laki & 75.800 & 2.581 & 70.714 & 80.886 \\
\cline { 2 - 6 } & Perempuan & 82.075 & 2.414 & 77.317 & 86.833 \\
\hline \multirow{2}{*}{ Batak } & Laki-laki & 86.500 & 2.788 & 81.006 & 91.994 \\
\cline { 2 - 6 } & Perempuan & 82.067 & 2.276 & 77.581 & 86.553 \\
\hline \multirow{2}{*}{ Jawa } & Laki-laki & 83.086 & 2.581 & 77.999 & 88.172 \\
\cline { 2 - 6 } & Perempuan & 87.487 & 2.445 & 82.669 & 92.306 \\
\hline
\end{tabular}

Berdasarkan Tabel 4 dapat diperoleh perbedaan hasil dari nilai mean masing-masing aspek. Pada budaya Melayu, hipotesis bahwa terdapat perbedaan self-disclosure siswa dalam konseling individu berdasarkan dari jenis kelamin guru BK/ konselor diterima. Hal ini terlihat dari perbedaan rata-rata jenis kelamin perempuan $(82,075)$ lebih besar atau dominan daripada lakilaki $(75,800)$. Jadi, dapat disimpulkan bahwa pada budaya Melayu guru BK berjenis kelamin perempuan lebih dominan dalam meningkatkan self-disclosure siswa dalam konseling individu daripada guru BK berjenis kelamin laki-laki.

Pada budaya Batak, hipotesis bahwa terdapat perbedaan self-disclosure siswa dalam konseling individu berdasarkan dari jenis kelamin guru BK juga diterima. Hal ini terlihat dari perbedaan rata-rata jenis kelamin perempuan $(82,067)$ yang lebih kecil daripada laki-laki (86,500). Dengan demikian, dapat disimpulkan bahwa pada budaya batak lebih dominan guru BK dengan jenis kelamin laki-laki daripada guru BK berjenis kelamin perempuan dalam meningkatkan self-disclosure siswa pada konseling individu.

Pada budaya Jawa, hipotesis terdapat perbedaan self-disclosure siswa dalam konseling individu berdasarkan dari jenis kelamin guru BK diterima. Hal ini terlihat dari perbedaan rata-rata jenis kelamin perempuan $(87,487)$ lebih besar atau dominan daripada laki-laki $(83,086)$. Dengan demikian, dapat disimpulkan guru BK Jawa lebih dominan jenis kelamin perempuan daripada guru BK berjenis kelamin laki-laki dalam meningkatkan self-disclosure pada konseling individu.

Self-disclosure siswa dalam konseling individu pada guru BK budaya Melayu lebih cenderung kepada guru BK perempuan. Hal ini berarti siswa lebih cenderung terbuka dengan guru BK jenis kelamin perempuan daripada guru BK berjenis kelamin laki-laki pada latarbelakang budaya Melayu. Self-disclosure siswa dalam konseling individu pada guru BK budaya Batak lebih 
dominan guru BK dengan jenis kelamin laki-laki. Hal ini berarti siswa lebih cenderung terbuka dengan guru BK jenis kelamin laki-laki daripada perempuan pada latarbelakang budaya Batak. Self-disclosure siswa dalam konseling individu pada guru BK budaya Jawa lebih dominan guru BK perempuan. Hal ini berarti siswa lebih terbuka dengan guru BK jenis kelamin perempuan daripada laki-laki pada latarbelakang budaya Jawa.

Hasil penelitian dapat diinterpretasikan bahwa siswa lebih cenderung terbuka ketika melakukan konseling kepada guru BK dengan jenis kelamin dan latar belakang perempuan JawaMelayu dan laki-laki Batak. Jika dibalik, guru BK perempuan Jawa-Melayu dan laki-laki Batak lebih mempengaruhi self-disclosure konseli dibandingkan berhadapan dengan jenis kelamin sebaliknya pada setiap budaya.

Bentuk perilaku siswa yang lebih terbuka tersebut dalam proses konseling individu kepada guru BK dapat dijelaskan di antaranya pada aspek keluasan, siswa merasa bebas menceritakan permasalahan yang dialami tanpa merasa terbebani. Pada aspek kedalaman, siswa berani mengungkapkan masalah pribadi yang dialaminya. Pada aspek target, siswa bersemangat menceritakan semua masalah pribadinya. Aspek ketepatan, siswa tetap menceritakan masalah yang dialaminya kepada guru BK yang berbeda jenis kelamin. Selanjutnya aspek waktu, siswa mampu berfikir positif setelah menceritakan permasalahannya kepada guru BK dalam pelaksanaan konseling individu.

Berdasarkan hasil penelitian, tingkat self-disclosure siswa lebih dominan kepada guru BK jenis kelamin perempuan yang memiliki latar belakang budaya Melayu dalam konseling individu. Menurut (Guru \& Pati, 2018) budaya yang dibawa guru BK mempengaruhi self-disclosure siswa dalam konseling. Hal ini sama dengan penelitian dari Zane \& Ku (2014) bahwa kecocokan etnis, kecocokan gender, akulturasi, identitas budaya, dan keprihatinan mempengaruhi self-disclosure dalam konseling individu untuk orang Amerika keturunan Asia.

Selanjutnya, self-disclosure siswa lebih dominan kepada guru BK jenis kelamin perempuan yang memiliki latar belakang budaya Jawa dalam konseling individu. Hal ini didukung dengan pendapat (Nurhayati, 2012) di mana siswa lebih terbuka kepada perempuan dikarenakan mereka menganggap perempuan seperti seorang ibu yang dapat membuat kondisi emosi menjadi stabil.

Berbeda dengan penelitian sebelumnya. Farinosi \& Taipale (2018) mengumpulkan tanggapan dari sampel 813 mahasiswa Italia (usia 18-34). Hasil penelitiannya menunjukkan bahwa responden lebih mengkhawatirkan privasi terhadap pengguna Facebook lain daripada terhadap aplikasi Facebook sebagai pihak ketiga. Wanita justru secara konsisten lebih memperhatikan risiko terkait privasi daripada pria yang dapat dikaitkan dengan upaya menjaga tenaga kerja digital dalam kehidupan sehari-hari.

Untuk latar belakang budaya Batak, guru BK jenis kelamin laki-laki lebih dominan dalam mempengaruhi self-disclosure konseli selama proses konseling individu. Hasil penelitian ini mendukung dengan hasil penelitian Siagian (2017) bahwa terdapat perbedaan pengungkapan diri konseli dalam konseling perorangan kepada konselor laki-laki dan konselor perempuan, di mana konseli laki-laki dan perempuan lebih terbuka kepada konselor laki-laki daripada konselor perempuan.

Keberhasilan dalam pelayanan konseling individu selain faktor kompetensi konselor, selfdisclosure juga sangat menentukan keberhasilan dan efektifitas dalam konseling individu. Menurut Willis (2017) kunci keberhasilan konseling individu terletak pada self-disclosure siswa selama proses konseling individu. Semakin terbuka konseli dalam mengungkapkan masalah pribadinya, maka tujuan dalam konseling individu akan tercapai. Menurut Masaviru, (2016) selfdisclosure berupa komunikasi verbal \& non verbal.

Faktor lingkungan memiliki peran penting dalam keberhasilan komunikasi individu yang meliputi: jenis kelamin, budaya, sosial ekonomi, stereotip, pola asuh, dan pendidikan (Septiani et al., 2019). Faktor-faktor yang mempengaruhi self-disclosure, di antaranya: 1) perbedaan gender, 2) Budaya (Tang et al., 2013), 3) kepercayaan (Taddei \& Contena, 2013). Dalam aspek Budaya di Indonesia sejak kecil anak dididik untuk tidak menceritakan sesuatu yang memalukan diri sendiri, keluarga, dan masyarakat kepada orang lain. Anak sudah dididik untuk tidak terbuka kepada orang lain (Nirwana, 2013). 
Terkait faktor gender, Zane \& Ku (2014) meneliti di antara orang Amerika keturunan Asia dalam proses konseling. Dari penelitian itu menghasilkan simpulan bahwa kecocokan gender antara konseli dan konselor memfasilitasi self-disclosure. Konseli bisa lebih terbuka dalam mengungkap nilai-nilai keyakinannya, perasaan pribadinya, kebiasaan pribadinya, hubungan dekatnya, dan bahkan mengungkap masalah seksual. Kecocokan gender yang dimaksud adalah konseli laki-laki dengan konselor laki-laki, konseli perempuan dengan konselor perempuan. Sebaliknya, konseli laki-laki dengan konselor perempuan, menghasilkan kurang luwesnya selfdisclosure konseli.

Studi Brown et al. (2018) pada 1.393 mahasiswa dengan penyakit mental di Universitas menggunakan tes mediasi yang dimoderasi untuk analisis data. Hasil studi menunjukkan bahwa stigma masyarakat berhubungan dengan self-disclosure mahasiswa yang memiliki penyakit mental, terutama bagi mahasiswa pria. Peningkatan beban stres yang dirasakan justru membuat mahasiswa tidak terbuka dan sulit self-disclosure. Mahasiswa pria sulit untuk mengungkapkan diri, mengungkapkan masalahnya, mengungkapkan stresnya karena ketakutan akan stigma masyarakat.

Kane et al. (2014) meneliti empat puluh enam keluarga yang tinggal bersama dengan cara meminta mereka menyelesaikan lima puluh enam hari buku harian. Bentuk pengungkapan diri membantu wanita untuk lebih rileks daripada pria. Self-disclosure setiap hari melindungi efek suasana hati negatif yang tinggi pada wanita, tetapi tidak untuk pria. Sebaliknya, self-disclosure yang tinggi pada pria justru membuat pria kurang nyaman.

Penelitian lain terkait gender yang dilakukan Sheldon (2013) pada 197 wanita dan 190 pria perguruan tinggi. Wanita lebih sering mengungkapkan perasaannya kepada teman dekatnya, baik secara tatap muka, maupun secara online di Facebook daripada pria. Pria akan berdiskusi lebih intim kepada teman Facebook yang baru saja didapatkan daripada wanita. Apapun medianya, baik pria, maupun wanita, akan mengungkapkan diri lebih banyak kepada orang yang mereka anggap lebih intim. Jika penelitian ini dihubungkan dalam penelitian saat ini, maka guru BK perlu menjalin kedekatan hubungan agar siswa dengan mudah self-disclosure kepada konselor dalam proses konseling. Walton \& Rice (2013) pun sepakat bahwa gender mempengaruhi self-disclosure. Berdasarkan analisis Walton \& Rice (2013) pada 3.751 tweet, diketahui bahwa media sosial membantu self-disclosure individu.

Self-disclosure individu di media sosial, khususnya, Facebook dipengaruhi oleh gender (Chang \& Heo, 2014). Stres juga mempengaruhi self-disclosure individu, terutama di media sosial. Individu lebih memilih mengungkapkan masalahnya daripada menyimpan privasinya. Hasil dari survei terhadap 556 mahasiswa di Hong Kong menunjukkan bahwa masalah privasi berhubungan negatif dengan jumlah, keintiman, dan kejujuran pengungkapan diri media sosial. Namun, tingkat stres seseorang meredam hubungan antara masalah privasi dan jumlah pengungkapan dan keintiman. Ini menunjukkan bahwa orang mungkin kurang khawatir tentang privasi ketika sangat stres. Selain itu, efek moderasi stres bervariasi berdasarkan jenis kelamin. Studi ini memberikan wawasan tentang komponen emosional manajemen privasi online (Zhang \& Fu, 2020).

Seperti yang diuraikan pada analisis penelitian ini di atas, guru BK perempuan JawaMelayu dan laki-laki Batak lebih mempengaruhi self-disclosure konseli. Hal ini berarti kebalikannya pada guru BK laki-laki Jawa-Melayu dan perempuan Batak. Pada guru BK dengan gender yang kurang menguntungkan pada budaya yang dibawanya, komunikasi melalui online dapat menjadi alternatif. Apalagi, di era sekarang cybercounseling sudah semakin berkembang.

Komunikasi dengan perbedaan gender di media sosial akan menghasilkan selfdisclosure yang lebih tinggi (Chen \& Sharma, 2015). Penelitian Wang et al. (2011) di Cina menghasilkan data bahwa komunikasi secara online membantu self-disclosure, tetapi tidak berhubungan dengan kualitas pertemanan. Pada gender laki-laki yang memiliki kecemasan sosial tinggi, komunikasi secara online membantu konseli untuk self-disclosure di proses konseling.

Media sosial, seperti Facebook, dipilih karena dapat meningkatkan self-disclosure dan pemeliharaan hubungan, walau dengan perbedaan gender. Pria dan wanita juga berbeda dalam tingkat pengungkapan diri secara keseluruhan serta jenis informasi yang disajikan di halaman Facebook mereka. Tingkat pengungkapan diri, tetapi bukan tingkat privasi, dikaitkan dengan 
tingkat kepuasan yang lebih tinggi dengan Facebook untuk memenuhi tujuan motivasi tertentu (Li-Barber, 2012).

Namun, berbeda ketika melakukan survei online. Self-disclosure dalam konseling secara online memang menjadi lebih tinggi. Akan tetapi, self-disclosure secara online tidak ikut baik untuk pertanyaan-pertanyaan survei yang sensitif. Pertanyaan-pertanyaan yang sensitif berpengaruh besar pada kesediaan individu menjawabnya, sehingga banyak data-data yang kosong (Kays et al., 2012).

Jadi, guru BK dengan gender yang kurang menguntungkan di budayanya, laki-laki Jawa, laki-laki Melayu, dan perempuan Batak dapat menggunakan konseling online untuk membantu meningkatkan self-disclosure siswa dalam konseling. Akan tetapi, hal ini tidak berlaku untuk penyebaran pengisian angket ataupun wawancara secara online pada pertanyaan-pertanyaan yang sensitif dan lebih mendalam pada individu.

Faktor kedua, yaitu faktor budaya. Smaldino (2014) mengemukakan budaya dapat didefinisikan secara historis tradisi-tradisi sebuah kelompok, secara normatif mengekspresikan aturan-aturan dan norma-norma sebuah kelompok, secara psikologis menekankan bagaimana sebuah kelompok melakukan pembelajaran dan memecahkan masalah, secara struktural menekankan elemen-elemen pengorganisasian sebuah budaya, dan secara genetis mendeskripsikan asal-usul budaya. Budaya berarti memiliki nilai normatif, genetis, historis, psikologis, dan struktural.

Budaya berkaitan erat dengan optimalnya proses konseling yang dijalankan. Konselor dituntut mampu memahami budaya dari konseli. Ketidakmampuan konselor dalam pemahaman budaya konseli akan memunculkan beberapa permasalahan. (Suardi, 2019) mengemukakan bahwa selain dihadapkan dengan dinamika sosiopolitikal yang dapat mempengaruhi layanan konseling, konselor perlu mendalami gangguan konseling beda budaya yang menyebabkan konseling atau bantuan profesional tidak efektif dan terjadinya gangguan proses konseling yang cukup masif.

Gangguan efektivitas layanan konseling beda budaya adalah adanya hambatanhambatan dalam proses layanan yang disebabkan oleh faktor perbedaan budaya, baik dalam diri klien sendiri atau perbedaan budaya antara klien dengan dengan konselor, sedangkan yang dimaksud dengan konseling beda budaya adalah proses layanan konseling yang terjadi dalam kontek klien yang berbeda budaya secara internal atau ekternal. Maka, diperlukan peningkatan kompetensi guru BK yang terkait dengan budaya, khususnya terkait multikultural.

Kompetensi yang harus dimiliki oleh guru BK terkait multikultural menurut (Khalilah, 2017; Sue et al., 2019), antara lain: guru BK harus memiliki kemampuan komunikasi, berinteraksi serta dapat memahami siswa dengan latar belakang budaya yang berbeda-beda. Dengan kata lain, dalam hal ini menuntut seorang guru BK harus dapat menumbuhkan rasa kepercayaan dari siswa dalam pelaksanaan layanan bimbingan konseling. Hal ini mirip dengan pendapat Nelyahardi et al., (2019) bahwa dalam proses konseling konselor hendaknya peka terhadap perbedaan budaya, suku, bahasa yang dibawa oleh konseli dalam proses konseling agar tujuan dalam konseling dapat terwujud, yaitu terentaskannya permasalahan konseli sehingga kehidupan konseli menjadi efektif dalam kesehariannya.

Lebih lanjut, Kartadinata (dalam Alizamar \& Afdal, 2016) menyebutkan bahwa guru BK harus memiiliki berbagai kompetensi dalam bidang konseling multikultural, dengan kompetensi yang disebut sebagai RESPECTFUL, yaitu diantaranya: $(R)$ religious-spiritual identity/ identitas spiritual-agama, (E) ethnic-cultural racial background/latar belakang etnis-budaya ras, $(S)$ sexual identity/identitas seksual, $(P)$ psychological maturity/kematangan psikologis, $(E)$ economic class background/ latar belakang kelas ekonomi, (C) chronological-developmental challenges/ tantangan perkembangan-kronologis, $(T)$ threats to one's personal well-being/ancaman terhadap well-being pribadi, (F) family history and dynamics/ riwayat dan dinamika keluarga, (U) unique physical characteristics/ ciri fisik yang unik, dan (L)location of residence/lokasi tempat tinggal.

$\mathrm{Hal}$ yang bertolak belakang dengan literatur dan penelitian ini adalah penelitian Zane \& $\mathrm{Ku}$ (2014). Penelitiannya mengungkap bahwa ternyata kecocokan budaya tidak mempengaruhi self-disclosure konseli. Misalnya, konseli keturunan Asia, sedangkan konselor keturunan Amerika. Konseli dapat dengan tetap mudah bercerita, meskipun berbeda budaya dengan konseli. 
Artinya, budaya tidak selalu mempengaruhi self-disclosure konseli. Self-disclosure konseli lebih dipengaruhi pada gender atau jenis kelamin. Pada proses konseling, konselor menemukan konseli yang sulit untuk bercerita, terutama karena perbedaan gender ataupun kurang pas dalam gender budayanya, konselor dapat menggunakan media sosial untuk melakukan cybercounseling. Tetapi dalam konteks pertanyaan-pertanyaan sensitif, bentuk ini kurang cocok digunakan. Terakhir, hal yang perlu menjadi perhatian dari analisis dan pembahasan di atas adalah konselor harus lebih memikirkan bagaimana membentuk kedekatan hubungan dengan konseli. Apa pun gendernya, apa pun budayanya, konselor harus hangat kepada siswa.

Hasil penelitian ini secara teknis dapat dijadikan dasar dalam pengembangan penelitian lanjutan yang berkaitan dengan self-disclosure siswa dalam konseling individu ditinjau dari aspek jenis kelamin dan budaya konselor yaitu budaya Melayu, Batak dan Jawa. Selanjutnya, secara praktis dapat dijadikan bahan pertimbangan guru BK dalam melaksanakan layanan konseling individu di sekolah yang lebih efektif. Dengan layanan konseling yang efektif, diharapkan guru BK dapat membantu siswa mencapai kehidupan yang lebih efektif dalam kesehariannya.

Berdasarkan hasil penelitian yang dilakukan, masih ada aspek yang belum terungkap berkaitan dengan self-disclosure siswa dalam konseling individu. Adapun aspek yang tidak diteliti dan perlu diungkap pada penelitian selanjutnya, antara lain: (1) Sampel penelitian ini adalah siswa yang pernah melakukan konseling individu dengan guru BK/ konselor. (2) Latarbelakang subjek penelitian dilihat berdasarkan perbedaan jenis kelamin siswa saja. Untuk latarbelakang budaya siswa belum diteliti, hal ini dapat dijadikan dasar penelitian selanjutnya. (3) Apakah latarbelakang budaya dan jenis kelamin konseli yang melakukan konseling memiliki jenis kelamin dan budaya yang sama dengan konselor atau tidak. (4) Latarbelakang guru BK atau konselor dilihat dari perbedaan jenis kelamin dan budaya yang dibawa guru BK/ konselor, di antaranya Melayu, Jawa dan Batak. Namun, perlu diteliti lagi aspek tempat tinggal guru BK/ konselor dan lingkungan guru BK/ konselor apakah sama dengan budaya yang dibawanya atau tidak. Implikasi pada peneliti selanjutnya, dapat menambahkan faktor kepribadian guru BK/konselor, agar dapat diketahui pengaruhnya terhadap keberhasilan konseling multikultural dan berbasis gender yang dilakukan.

Keterbatasan hasil penelitian ini adalah hasil penelitian belum tentu bisa digeneralisir pada suku yang sama di tempat lain. Variabel gender (laki-laki dan perempuan) serta variabel suku budaya guru BK (Melayu Jambi, Jawa, dan Batak) tidak selalu mempengaruhi selfdisclosure siswa dalam proses konseling setiap saat. Banyak faktor yang bisa menentukan hasil penelitian self-disclosure. Sementara itu, penelitian komparatif tidak memperhitungkan situasi banyak penyebab yang mungkin terjadi. Keterbatasan hasil penelitian kedua adalah arah kausalitas atau hubungan sebab akibat bisa jadi menjadi terbalik-mana yang sebab dan mana yang akibat-atau bisa saling mempengaruhi.

\section{Simpulan}

Simpulan yang dapat diambil adalah pada budaya Batak self-disclosure lebih dominan pada guru BK berjenis kelamin laki-laki. Berbeda dengan guru BK yang memiliki latar belakang budaya suku Melayu dan Jawa, self disclosure siswa lebih cenderung kepada Guru BK berjenis kelamin perempuan. Hal ini berarti siswa lebih terbuka dengan guru BK berjenis kelamin perempuan pada budaya Melayu, laki-laki pada budaya Batak, dan perempuan pada budaya Jawa. Temuan penelitian ini penting dan bermanfaat dalam pengembangan ilmu maupun praktik dunia konseling individu. Hal ini dikarenakan, konseling multikultural harus dipahami oleh konselor demi kelancaran proses konseling. Artikel ini menjadi sebuah temuan bahwa dari ketiga budaya guru BK tersebut, jenis kelamin guru BK memberikan pengaruh berbeda-beda terhadap self-disclosure siswa dalam pelaksanaan konseling individu. 


\section{Ucapan Terima Kasih}

Terimakasih kepada Universitas Jambi yang telah mendanai penelitian ini melalui DIPAPNBP Fakultas Keguruan dan IImu Pendidikan skema penelitian tahun 2020.

\section{Daftar Rujukan}

Alizamar, A., \& Afdal, A. (2016). Faktor Budaya dalam Kreativitas dan Upaya Konselor dalam Peningkatannya.

Auladi, I. N. (2019). HUBUNGAN PERILAKU ANTISOSIAL DENGAN KETERBUKAAN DIRI (SELF DISCLOSURE) SISWA KELAS XI SMA NEGERI 2 KEBUMEN TAHUN PELAJARAN 2018/2019. Universitas Negeri Semarang.

Barnett, J. E. (2011). Psychotherapist self-disclosure: Ethical and clinical considerations. Psychotherapy, 48(4), 315.

Baruth, L. G., \& Manning, M. L. (2016). Multicultural counseling and psychotherapy: A lifespan approach. Routledge.

Bitar, G. W., Kimball, T., Bermúdez, J. M., \& Drew, C. (2014). Therapist self-disclosure and culturally competent care with Mexican-American court mandated clients: A phenomenological study. Contemporary Family Therapy, 36(3), 417-425.

Brown, R. L., Moloney, M. E., \& Brown, J. (2018). Gender differences in the processes linking public stigma and self-disclosure among college students with mental illness. Journal of Community Psychology, 46(2), 202-212.

Chalidaziah, W., Nirwana, H., \& Alizamar, A. (2018). Student's self-disclosure.

Chang, C.-W., \& Heo, J. (2014). Visiting theories that predict college students' self-disclosure on Facebook. Computers in Human Behavior, 30, 79-86.

Chen, R., \& Sharma, S. K. (2015). Learning and self-disclosure behavior on social networking sites: the case of Facebook users. European Journal of Information Systems, 24(1), 93-106.

Christiana, R. (2016). Self Disclosure-based Family Counseling Theory to Enhance Harmony Multicultural Family Background. Proceedings International Seminar FoE (Faculty of Education), 287-293.

Corey, G. (2017). Theory and practice of counseling and psychotherapy. Nelson Education.

Farinosi, M., \& Taipale, S. (2018). Who Can See My Stuff?: Online Self-Disclosure and Gender Differences on Facebook. Observatorio $\left(O B S^{*}\right), 12$.

Forest, A. L., \& Wood, J. V. (2012). When social networking is not working: Individuals with low self-esteem recognize but do not reap the benefits of self-disclosure on Facebook. Psychological Science, 23(3), 295-302.

Forgas, J. P. (2011). Affective influences on self-disclosure: Mood effects on the intimacy and reciprocity of disclosing personal information. Journal of Personality and Social Psychology, 100(3), 449.

Gamayanti, W., Mahardianisa, M., \& Syafei, I. (2018). Self disclosure dan tingkat stres pada mahasiswa yang sedang mengerjakan skripsi. Psympathic: Jurnal IImiah Psikologi, 5(1), $115-130$.

Gibson, M. F. (2012). Opening up: Therapist self-disclosure in theory, research, and practice. Clinical Social Work Journal, 40(3), 287-296.

Guru, B. K., \& Pati, G. (2018). PERMASALAHAN SISWA DI ERA DISRUPSI: GURU DAN BUDAYA PENDIDIKAN BERBASIS BIMBINGAN DAN KONSELING. Prosiding, 129.

Hadiwinarto, H. (2018). Konseling Lintas Budaya Berbasis Sumber Daya Lokal dan Kebencanaan. Jurnal Bimbingan Dan Konseling Terapan, 2(1).

Hamilton, L., \& Ravenscroft, J. (2018). Building research design in education: Theoretically informed advanced methods. Bloomsbury Publishing.

Heath, P. J., Vogel, D. L., \& Al-Darmaki, F. R. (2016). Help-seeking attitudes of United Arab Emirates students: Examining loss of face, stigma, and self-disclosure. The Counseling Psychologist, 44(3), 331-352.

Hermawan, I. (2019). Metodologi Penelitian Pendidikan (Kualitatif, Kuantitatif dan Mixed Method). 
Hidayatul Quran.

Hill, C. E., Knox, S., \& Pinto-Coelho, K. G. (2018). Therapist self-disclosure and immediacy: A qualitative meta-analysis. Psychotherapy, 55(4), 445.

Hodiyanto, H. (2017). Pengaruh model pembelajaran problem solving terhadap kemampuan komunikasi matematis ditinjau dari gender. Jurnal Riset Pendidikan Matematika, 4(2), 219228.

Horne, R. M., \& Johnson, M. D. (2018). Gender role attitudes, relationship efficacy, and selfdisclosure in intimate relationships. The Journal of Social Psychology, 158(1), 37-50.

Irshad, S. (2011). Study of general mental health in relation to Self-Disclosure, ExtraversionIntroversion and social support. Aligarh Muslim University.

Kane, H. S., Slatcher, R. B., Reynolds, B. M., Repetti, R. L., \& Robles, T. F. (2014). Daily selfdisclosure and sleep in couples. Health Psychology, 33(8), 813.

Kays, K., Gathercoal, K., \& Buhrow, W. (2012). Does survey format influence self-disclosure on sensitive question items? Computers in Human Behavior, 28(1), 251-256.

Kesumadewi, E. S. (2018). Perbedaan Model Komunikasi Kepala Sekolah Menurut Persepsi Siswa Ditinjau dari Perspektif Gender. Jurnal IImu Pendidikan (JIP) STKIP Kusuma Negara, 9(2), 75-84.

Khalilah, E. (2017). Layanan bimbingan dan konseling pribadi sosial dalam meningkatkan keterampilan hubungan sosial siswa. JIGC, 1(1), 41-57.

Kim, J., \& Dindia, K. (2011). Online self-disclosure: A review of research. Computer-Mediated Communication in Personal Relationships, 156-180.

Levitt, H. M., Minami, T., Greenspan, S. B., Puckett, J. A., Henretty, J. R., Reich, C. M., \& Berman, J. S. (2016). How therapist self-disclosure relates to alliance and outcomes: A naturalistic study. Counselling Psychology Quarterly, 29(1), 7-28.

Li-Barber, K. T. (2012). Self-disclosure and student satisfaction with Facebook. Computers in Human Behavior, 28(2), 624-630.

Mangkunegara, A. A. A. P., \& Puspitasari, M. (2015). Kecerdasan emosi guru, stres kerja, dan kinerja guru SMA. Jurnal Kependidikan: Penelitian Inovasi Pembelajaran, 45(2).

Masaviru, M. (2016). Self-disclosure: Theories and model review. Journal of Culture, Society and Development, 18, 43-47.

Mitchell, M. H., \& Gibson, R. L. (2011). Introduction to counseling and guidance. Yogyakarta: Pustaka.

Morman, M. T., Schrodt, P., \& Tornes, M. J. (2013). Self-disclosure mediates the effects of gender orientation and homophobia on the relationship quality of male same-sex friendships. Journal of Social and Personal Relationships, 30(5), 582-605.

Nelyahardi, N., Sarman, F., Wahyuni, H., \& Randani, R. (2019). The Process of Verbal Communication in Ethnic Malay and Batak: A Case Study. 5th International Conference on Education and Technology (ICET 2019), 638-641.

Nirwana, H. (2013). Pengungkapan Diri Siswa Sekolah Menengah dan Implikasinya Bagi Konseling. Jurnal IImu Pendidikan, 18(1).

Nöstlinger, C., Bakeera-Kitaka, S., Buyze, J., Loos, J., \& Buvé, A. (2015). Factors influencing social self-disclosure among adolescents living with HIV in Eastern Africa. AIDS Care, 27(sup1), 36-46.

Nurhayati, E. (2012). Psikologi perempuan dalam berbagai perspektif. Pustaka Pelajar.

Quek, K. M.-T., \& Fitzpatrick, J. (2013). Cultural values, self-disclosure, and conflict tactics as predictors of marital satisfaction among Singaporean husbands and wives. The Family Journal, 21(2), 208-216.

Reno, R. R., \& Kenny, D. A. (1992). Effects of self-consciousness and social anxiety on selfdisclosure among unacquainted individuals: An application of the social relations model. Journal of Personality, 60(1), 79-94.

Septiani, D., Azzahra, P. N., Wulandari, S. N., \& Manuardi, A. R. (2019). SELF DISCLOSURE DALAM KOMUNIKASI INTERPERSONAL: KESETIAAN, CINTA, DAN KASIH SAYANG. FOKUS (Kajian Bimbingan \& Konseling Dalam Pendidikan), 2(6), 265-271.

Sheldon, P. (2013). Examining gender differences in self-disclosure on Facebook versus face-toface. The Journal of Social Media in Society, 2(1). 
Siagian, K. (2017). Pengungkapan Diri Klien dalam Konseling Perorangan. Universitas Negeri Padang.

Silfia, H. (2017). Komunikasi Antarpribadi: Teori dan Praktik. Ar-Ruzz media.

Smaldino, P. E. (2014). The cultural evolution of emergent group-level traits. Behavioral and Brain Sciences, 37(3), 243-295.

Suardi, S. (2019). Hambatan Efektifiktas Layanan Konseling Beda Budaya. Konvensi Nasional Bimbingan Dan Konseling XXI, 35-38.

Sue, D. W., Sue, D., Neville, H. A., \& Smith, L. (2019). Counseling the culturally diverse: Theory and practice. John Wiley \& Sons.

Sukarman, S. (2020). PENGARUH LAYANAN KONSELING INDIVIDU TERHADAP PERILAKU EGOIS SISWA. Jurnal Paedagogy, 2(2), 70-75.

Sunderani, S., \& Moodley, R. (2020). Therapists' perceptions of their use of self-disclosure (and nondisclosure) during cross-cultural exchanges. British Journal of Guidance \& Counselling, 48(6), 741-756.

Taddei, S., \& Contena, B. (2013). Privacy, trust and control: Which relationships with online selfdisclosure? Computers in Human Behavior, 29(3), 821-826.

Tang, N., Bensman, L., \& Hatfield, E. (2013). Culture and sexual self-disclosure in intimate relationships.

Wahyuni, S. (2018). Penerapan Komunikasi Pengungkapan Diri (Self Disclosure) Muslimah Bercadar di Fakultas Dakwah dan Komunikasi. Universitas Islam Negeri Alauddin Makassar.

Walton, S. C., \& Rice, R. E. (2013). Mediated disclosure on Twitter: The roles of gender and identity in boundary impermeability, valence, disclosure, and stage. Computers in Human Behavior, 29(4), 1465-1474.

Wang, J.-L., Jackson, L. A., \& Zhang, D.-J. (2011). The mediator role of self-disclosure and moderator roles of gender and social anxiety in the relationship between Chinese adolescents' online communication and their real-world social relationships. Computers in Human Behavior, 27(6), 2161-2168.

Widiarni, Y. (2020). Penerapan Layanan Konseling Individual Dalam Penanganan Problem Emosional Siswa di MAN $1 P$ amekasan. Institut Agama Islam Negeri Madura.

Willis, S. S. (2017). Konseling individual, teori dan praktek.

Wood, J. (2012). Gendered lives. Nelson Education.

Ying, L. Y., Thai, Y. N., \& Sathivellu, M. F. (2016). An Exploration Study of Self-Disclosure Communicative Strategies to Enact Friendship in Facebook Wall Posts. International Review of Management and Marketing, 6(8S).

Yusuf, S. (2016). Konseling individual konsep dasar \& pendekatan. Bandung: Refika Aditama.

Zane, N., \& Ku, H. (2014). Effects of ethnic match, gender match, acculturation, cultural identity, and face concern on self-disclosure in counseling for Asian Americans. Asian American Journal of Psychology, 5(1), 66.

Zhang, R., \& Fu, J. S. (2020). Privacy Management and Self-Disclosure on Social Network Sites: The Moderating Effects of Stress and Gender. Journal of Computer-Mediated Communication, 25(3), 236-251.

Ziv-Beiman, S. (2013). Therapist self-disclosure as an integrative intervention. Journal of Psychotherapy Integration, 23(1), 59.

Zulamri, Z. (2019). Pengaruh Layanan Konseling Individual Terhadap Keterbukaan Diri (Self Disclosure) Remaja Di Lembaga Pembinaan Khusus Anak Klas II B Pekanbaru. At-Taujih: Bimbingan Dan Konseling Islam, 2(2), 19-36.

\section{Competing interests:}

The authors declare that they have no significant competing financial, professional or personal interests that might have influenced the performance or presentation of the work described in this manuscript. 